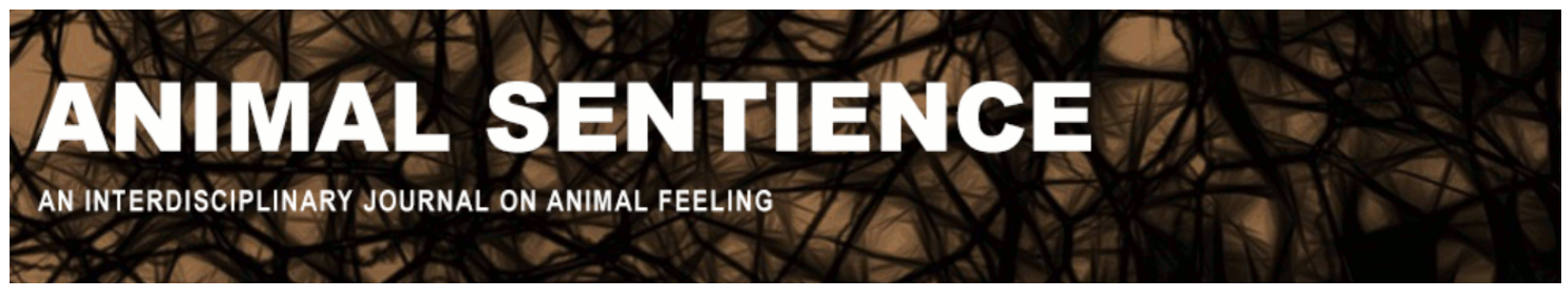

Leadbeater, Simon (2017) Will the precautionary principle broaden acceptance of animal sentience?. Animal Sentience 16(16)

DOI: $10.51291 / 2377-7478.1258$

Date of submission: $2017-11-17$

Date of acceptance: 2017-11-23

(c)

This article has appeared in the journal Animal

Sentience, a peer-reviewed journal on animal

cognition and feeling. It has been made open access,

free for all, by WellBeing International and deposited

in the WBI Studies Repository. For more information,

please contact

wbisr-info@wellbeingintl.org.

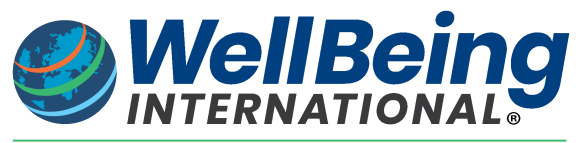

SOLUTIONS FOR PEOPLE, ANIMALS AND ENVIRONMENT 


\title{
Will the precautionary principle broaden acceptance of animal sentience?
}

\author{
Commentary on Birch on Precautionary Principle
}

\author{
Simon Leadbeater \\ Independent Environmental Consultant
}

\begin{abstract}
Birch uses existing practice to develop a formal Animal Sentience Precautionary Principle (ASPP), which he hopes will become more widely adopted and improve animal welfare outcomes. Birch considers the assumption that all animals are sentient to be extreme. Despite its merits, Birch's ASPP remains human-centred.
\end{abstract}

\begin{abstract}
Simon Leadbeater is an independent consultant and researcher. He has written for the Ecologist, the Voluntary Sector Review, Hertfordshire Life, The Quarterly Journal of Forestry, and ECOS, the Journal of the British Association of Nature Conservationists. His book, The Politics of Textiles, was published by Sage Publications. His main challenge lies in restoring an ancient woodland. priorsenvironmental.com
\end{abstract}

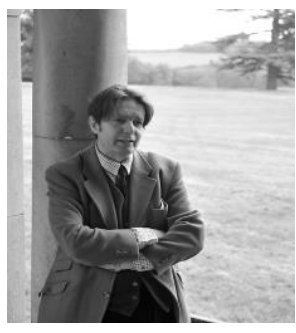

Birch (2017) borrows the United Nations definition of the precautionary principle in order to create the Animal Sentience Precautionary Principle (ASPP). Applying ASPP requires two conditions: the burden of proof - which has a low evidential bar - and a decision rule - based on timely cost-effective measures to prevent negative animal welfare outcomes. Birch states that the Animal Health and Animal Welfare Panel of the European Food Standards Agency are adopting similar approaches. He then tackles a number of counterarguments well.

In reading Birch's target article, the first questions I asked were, what assumptions does the author make? what problem is he trying to resolve? what gaps in our knowledge and understanding is he trying to fill? and what difference is his proposal going to make? I will attempt to address the first of these questions and then consider the issue of 'making a difference' towards the end of this commentary.

Birch makes explicit his assumption that not all animals are sentient and that an 'evidential bar for sentience' is required. He feels that universal animal sentience would be an 'extreme proposal' and 'anti-scientific' if it included species such as nematodes because it might create obstacles to research. His implicit assumption is that it is acceptable to use non-human animals to advance human-animal ends. Birch states his goal:

My aim is not to convince the critics ... but rather to articulate, for those already sympathetic to the precautionary principle, what its application in a particular context actually requires.

Birch's purpose, as I understand it, is not to challenge, or to advance understanding, but rather to formalise and encourage the application of an accepted principle (or one nearing acceptance), to refine and improve. He believes his principle is 'well-aligned' but wishes to 'articulate and make [it] precise.' 
Extreme presumption of sentience. I have some difficulty with Birch's argument that there cannot be a 'default presumption of sentience.' I think animal sentience is a matter of degree, not kind; in other words, I find it hard to accept that some animals have no sentience; I think all have some degree of sentience. In commenting on Key's (2016) argument that fish cannot feel pain, Safina (2016) argues that Key ignores evolution whose 'main message and effect is the continuity of life.' He explains that the same neural mechanisms are at work in nematodes as in humans: sentience is on a 'sliding scale.' Instead of Birch's ASPP, I prefer the Animal Sentience Presumption Principle (ASPresP). I am not sure why this should constitute an extreme proposal or would undermine animal sentience science - a high evidential bar to indicate nonsentience could substitute for Birch's low evidential bar suggesting sentience.

I also struggle with Birch's human-centred assumption that non-human animals can be considered in functional ways. The word 'welfare' (deployed 24 times) is suggestive, and has been described as a 'dirty little lie' denoting something unpleasant being done to non-human animals (Bekoff and Pierce, 2017). Of course, the aim behind Birch's proposal is to improve welfare, but perhaps only up to a point. Birch refers to 'cost-effective' means to prevent 'seriously bad outcomes,' but I am left asking what if the means are not cost-effective. He also does not wish to create 'significant practical obstacles to biomedical research' by deeming fruit flies and nematode worms sentient. But what if they are, as Emmons (2012) seems to suggest of nematodes; what then?

Application of ASPP vs. how we treat animals with known and undisputed sentience. It can only be a good thing if the adoption of Birch's proposal means that a greater number of animals are included within a framework governed by ASPP, suggesting their sentience becomes a consideration whereas previously it would not have been. And if 'making precise' establishes an industry standard, then, notwithstanding my earlier observations about ASPresP, that would also represent progress. That said, the precautionary approach has limited application when scientific investigation touches the debate concerning where sentience thresholds begin and end. Birch states that the order of Octopoda should be considered sentient and therefore ASPP will apply, but burdens of proof would be required for jawless fish (lampreys and hagfish) and cartilaginous fish. There is another much more significant principle to consider here, namely the Animal Sentience Principle (ASP), which concerns treating (or leaving alone) animals based on their known and undisputed sentience. If we agree with Birch when he says, 'as a rule of thumb ... a greater degree of sentience should imply a greater degree of regularity oversight,' then the obvious question is: where is this oversight being exercised for the 1 to 3 trillion fish caught for human consumption when their sentience is not in doubt (Sneddon, 2003). Theorists concerned with animal sentience should seek to overcome what Bekoff and Pierce (2017) call the 'knowledge translation gap,' ignoring the science of sentience in the treatment of animals.

What difference will ASPP make? Non-human animals should be treated in accordance with their sentience (or degrees thereof); legislation and regulation should reflect this. While full ASP still remains far off, ASPP, in highlighting sentience, is bridging the 'knowledge translation gap' to some extent. One wonders, however, to what extent the author believes in the destination given his human-centred view that ASP is 'extreme.' 


\section{References}

Bekoff, M., and Pierce, J. (2017) The Animals' Agenda: Freedom, Compassion, and Coexistence in the Human Age. Beacon Press.

Birch, J. (2017) Animal sentience and the precautionary principle. Animal Sentience 16(1).

Emmons, S.W. (2012). The mood of a worm. Science, 338: 475-476. In: Safina, C. (2015), Beyond Words, p. 32.

Key, B. (2016) Why fish do not feel pain. Animal Sentience 3(1).

Safina, C. (2015) Beyond Words. Henry Holt and Company.

Safina, C. (2016) Fish pain's burden of proof. Animal Sentience 3(45).

Sneddon, L., Braithwaite, V.A., and Gentle, M.J. (2003) Do fish have nocieceptors? Evidence for the evolution of a vertebrate sensory system. Proceedings of the Royal Society, 270(1520): $1115-1121$.

Sonar. (March 21, 2017). The Animals' Agenda: Exclusive Interview with Marc Bekoff and Jessica Pierce. 